\title{
Nachrichtentechnische Kolloquien
}

Vor mehr als dreißig Jahren wurde zum letzten Mal an der Technischen Universität in Wien ein Nachrichtentechnisches Kolloquium veranstaltet. Damals war es der leider schon verstorbene Prof. Günther Kraus, der anlässlich seines 65. Geburtstags und seiner Emeritierung die Schirmherrschaft über diese wissenschaftliche Veranstaltung übernahm, welche OVE und VDE mit unterstützten.

Es scheint an der Zeit, diese Kolloquien wieder aufzunehmen, und es bietet sich eine sehr ähnliche Gelegenheit: Diesmal ist es Prof. Hans Weinrichter, der diese Schwelle erreicht hat. Alle staunen, dass es schon so weit ist: Wie schnell ist die Zeit vergangen, wie schnell sind dreißig Jahre vergangen!

In der Nachrichtentechnik hat sich Enormes zugetragen, und die Übertragungstechnik war - wie schon in der früheren Vergangenheit - der Motor des Fortschritts. Vom Filter zur Codierung, vom Computer zur Signalverarbeitung, vom Festnetz zum Mobiltelefon - jedermann hat diese Neuerungen in der Hand, benutzt sie, ohne viel darüber zu wissen.

Am 28. Juni 2005 findet das erste Nachrichtentechnische Kolloquium der neuen Reihe statt, und es wird Weinrichter anlässlich seines 65 . Geburtstags und seiner Pensionierung ehren.

Namhafte Persönlichkeiten werden berichten, über Erreichtes und noch zu Erreichendes, über Probleme, Lösungen und Visionen; denn die Nachrichtentechnik steht vor neuen Herausforderungen. Der anscheinende Überfluss an Bandbreite auf Lichtwellenleitern, die schier unbegrenzte Prozessorleistung und Speicherkapazität bescheren eine Fülle, die nach der ordnenden Hand des soliden Ingenieurs ruft. Dass Informatiker dafür nach der Zeitscheibentechnik der Nachrichtentechnik greifen, ist ein Wegweiser. Von „Embedded Systems“" zu "Gridcomputing" werden von der Nachrichtentechnik informationstechnische Systemlösungen verlangt: Der Nachrichtentechniker muss auch Computerfachmann und Systemtechniker sein und sich

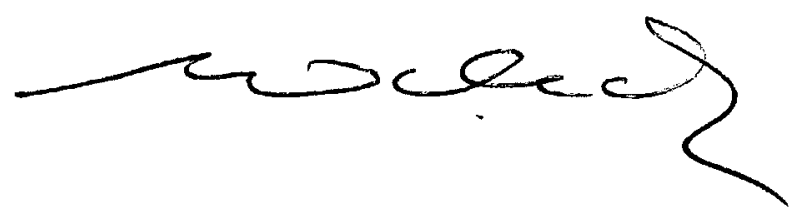

Helmut Malleck

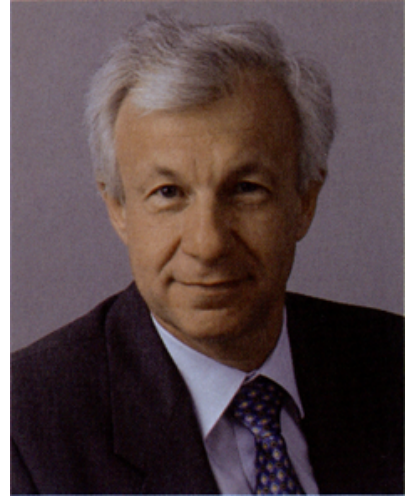

Dr. Helmut Malleck

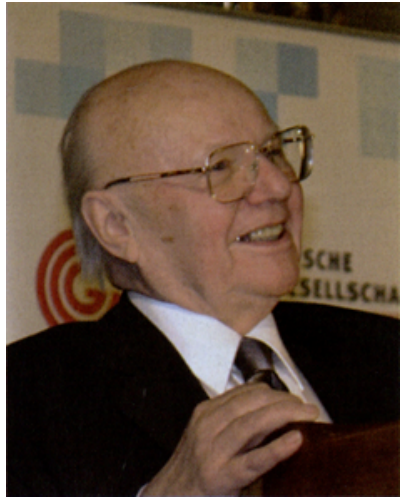

O. Univ.-Prof. Dr. Heinz Zemanek ständig weiterbilden. Dazu soll die neue Reihe der Nachrichtentechnischen Kolloquien verhelfen, und der gesamte Kollegenkreis ist eingeladen!

Könnten wir dreißig Jahre in die Zukunft blicken, ins Jahr 2035, würden wir in einem solchen Nachrichtentechnischen Kolloquium (vielleicht müsste es in diesem Jahr auch wieder neu gestartet werden!) Fachleute der Picotechnologie, der dynamischen Systeme und vielleicht weiterer, heute noch unbekannter Fachgebiete an einem Tisch beisammen finden, wie sie die Titel der neuen Serie ausknobeln. Der österreichische Ingenieurgeist ist heute für die Erneuerung hervorragend ausgebildet, und er wird es auch in dreißig Jahren sein.

Der OVE, diesmal auch in Kooperation mit dem VDE, wünscht dem Nachrichtentechnischen Kolloquium viel Erfolg! Möge es ein weiterer Meilenstein sein. Österreich braucht diese Form der Weiterbildung, denn Naturwissenschaft und Technik werden ihr Tempo beibehalten, und unser Land muss dabei Schritt halten.

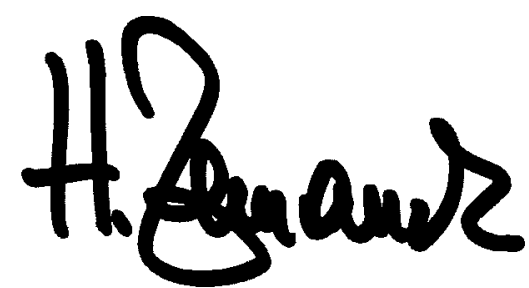

Heinz Zemanek 